\title{
The Effects of Tuberculosis Treatment on Quality of Life, Anxiety and Depression
}

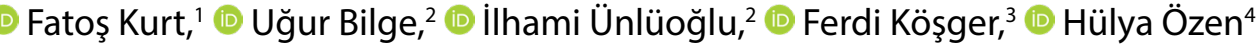 \\ 'Sehbal Baydur Family Health Center, Mugla, Turkey \\ ${ }^{2}$ Department of Family Medicine, Eskisehir Osmangazi University Faculty of Medicine, Eskisehir, Turkey \\ ${ }^{3}$ Department of Psychiatry, Eskisehir Osmangazi University Faculty of Medicine, Eskisehir, Turkey \\ ${ }^{4}$ Department of Biostatistics, Eskisehir Osmangazi University Faculty of Medicine, Eskisehir, Turkey
}

\section{ABSTRACT}

Objectives: This study aims to observe the health-related quality of life and depression and anxiety symptoms of newly diagnosed patients who were taking four-drug anti-tuberculosis (anti-TB) therapy during the treatment period.

Methods: The TB-diagnosed patients who were taking four-drug TB therapy and suitable for this study were followed up during the treatment period in the providence of Eskişehir. The patients were assessed according to the Short From-36 (SF-36) health quality, Beck depression, and Beck anxiety scales at three months and at the end of this study (six months).

Results: Significant improvements were observed in all SF-36 components at the end of this study $(p<0.001)$. When compared with the beginning and the end of the treatment, there was a statistically significant decrease in Beck depression and anxiety scores $(p<0.001)$.

Conclusion: Improvement in the patients' Beck depression-anxiety and life quality scores without additional psychiatric treatment is an important finding. These scientific outcomes show that, like other chronic diseases, TB may cause psychiatric problems.

Keywords: Anxiety, depression, tuberculosis, quality of life

\section{INTRODUCTION}

Tuberculosis (TB) is a chronic infectious disease that has threatened public health since ancient times. Although TBis preventable and curable, TB continues to be a major global health problem that affects millions of people every year. ${ }^{[1,2]}$ The disease causes the deterioration of quality of life and triggers anxiety in patients because of social challenges. Anxiety disorders and depression are the most common mental disorders associated with chronic respiratory

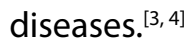

Accepted Date: 22.08.2019

Published online: 21.08 .2020

(C) Copyright 2020 by Anatolian Journal of Family Medicine Available online at WwW.anatoljfm.org OPEN ACCESS

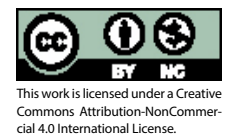

TB may have an impact on all components of the quality of life, including the general perception of health, bodily sensations, mental health and physical, social, and role-based functionality. Concerning social challenges, the problems that are likely to develop because of TB are social stigma, loneliness, drug side effects, long-term therapy, sexual dysfunction, and loss of income. ${ }^{[5-7]}$ There is limited research on mental disorders in patients with TB, although TB may cause fear of social stigma as soon as the patient is diagnosed. Based on the hypothesis that the process of treatment affects the quality of life and mental health, this study aims to assess the quality of life, anxiety, and depression in newly diagnosed patients with TB undergoing 
first-line anti-TB treatment during a total treatment period of six months.

\section{METHOD}

This prospective study was based on clinical observations of patients during treatment. Permission was received from the Directorate of Public Health in Eskişehir to conduct this study in the Tuberculosis Control Dispensary (TCD). This study was conducted between November 2014 and November 2015 among patients with a definitive diagnosis of TB, who were admitted to the TCD for anti-TB treatment, and who fully adhered to the treatment regime during a standard 6-month treatment course. Patients who were younger than 18 years of age, were not willing to participate in this study or had a cognitive disorder were not included in this study. The following forms were completed for each patient before the commencement of treatment and in the $3^{\text {rd }}$ and $6^{\text {th }}$ months of treatment.

\section{Measurements}

Sociodemographic Data Form: This form was developed by the researchers to collect data on the patients' demographic characteristics.

Short Form-36 (SF-36): This form consisted of 36 items that allowed the assessment of eight dimensions: physical functioning (PF), social role functioning (SF), physical role functioning $(P R)$, emotional role functioning (ER), mental health $(\mathrm{MH})$, vitality $(\mathrm{V})$, bodily pain $(\mathrm{BP})$, and general health perceptions $(\mathrm{GH})$. Each subscale is scored between 0 and 100, where 0 indicates poor health condition, and 100 indicates no disability. ${ }^{[8,9]}$ The reliability and validity of the instrument in Turkish weretested. ${ }^{[10]}$

Beck Depression Inventory (BDI): The BDI is a self-reporting instrument that measures the degree of depressive symptoms. ${ }^{[11]}$ The instrument comprises 21 questions, each of which represents a certain category of symptom and is scored from 0 to 3 . The instrument was tested for reliability and validity. ${ }^{[12]}$

Beck Anxiety Inventory (BAI): The 21-item BAI is an instrument to determine the degree of anxiety symptoms. ${ }^{[13]}$ The total score of the instrument ranges between 0 and 63 . BAI was translated into Turkish by Ulusoy et al. ${ }^{[14]}$

\section{Statistical Analysis}

IBM SPSS 21 software was used for data analyses. The Shapiro-Wilk test was used to check the data for the normal distribution. The categorical variables were presented in the form of frequency and percentages, and continuous variables were presented as median (min-max). The Friedman test was performed to compare repeated measures. Post hoc analysis were performed with Wilcoxon signed-rank tests with Bonferroni corrections. Results were considered statistically significant at $p<0.05$.

\section{RESULTS}

This study was conducted with 63 patients who were recently diagnosed with TB and had started anti-TB treatment. The number of patients who completed the first survey was $58(92.1 \%)$, and the number who completed the second survey was 54 (85.7\%). Of 63 patients who filled out the first set of surveys, $5(7.9 \%)$ patients were excluded from this study, i.e., 2 (3.2\%) patients were no longer diagnosed with TB, 1 (1.6\%) patient died, 1 (1.6\%) patient moved out of town, and $1(1.6 \%)$ patient failed to continue treatment. Of the $58(92.1 \%)$ patients who completed the second set of surveys, 4 (6.9\%) patients were excluded from this study, i.e., $1(1.7 \%)$ patient died, and 3 (5.2\%) patients dropped out. Of $54(85.7 \%)$ patients who participated in the entire study, 33 (61.1\%) were men, and 21 (38.9\%) were women. In the group, 42 (77.8\%) patients were married, 8 (14.8\%) patients were single, and $4(7.4 \%)$ patients were divorced or widowed. The results related to educational background were as follows: 3 (5.6\%) patients were illiterate, 35 (64.8\%) patients had primary school degrees, 10 (18.5\%) patients had high school degrees, and 6 (11.1\%) patients had higher education degrees. Monthly income was below $850 \mathrm{TL}$ in 12 (22.2\%) patients, between 850 and 1000 TL in 14 (25.9\%) patients, between 1000 and 2500 TL in 23 (42.6\%) patients, and over $2500 \mathrm{TL}$ in 5 (9.3\%) patients. In the patient group, $23(42.6 \%)$ patients had at least one additional chronic disease, whereas 31 (57.4\%) patients had no additional chronic diseases.

The comparative statistical analysis results of the three surveys for the first four subscales of SF-36 indicate a statistically significant increase between the first and the third survey results concerning all subscales, i.e., PF, PR, BP and $\mathrm{GH}$. There was also a statistically significant increase between the first and the second surveys in $\mathrm{GH}$ and BP subscales and between the second and the third surveys in the PF subscale (Table 1).

The comparative statistical analysis shows a statistically significant increase between all measurements concerning $\mathrm{V}$, SF, and MH subscales of SF- 36 and only a statistically significant increase between the first and third measurements concerning ER score (Table 1).

The comparative analyses of physical health component (PHC) and mental health component (MHC) -two main components of SF-36- suggest a statistically significant increase between the first and second survey results and between 
Table 1. Comparative statistical analysis results for SF-36, BDI and BAI scores in all patients (in months 0, 3 and 6 )

\begin{tabular}{|c|c|c|c|c|c|c|}
\hline & Month 0 (1) & Month 3 (2) & Month 6 (3) & $p(1-2)^{*}$ & $p(1-3)^{*}$ & p (2-3)* \\
\hline SF36 PR & $35.0(28.0-56.2)$ & $56.2(28.0-56.2)$ & $56.2(28.0-56.2)$ & 0.103 & $<0.001$ & 0.146 \\
\hline SF36 GH & $45.3(26.5-60.3)$ & $50.4(26.5-60.3)$ & $53.2(32.2-62.6)$ & $<0.001$ & $<0.001$ & 0.004 \\
\hline SF36 V & $40.8(30.1-63.3)$ & $53.8(32.5-65.6)$ & $58.5(34.9-65.6)$ & $<0.001$ & $<0.001$ & 0.007 \\
\hline SF36 ER & $55.3(23.7-55.3)$ & $55.3(23.7-55.4)$ & $55.3(23.7-55.3)$ & 0.103 & 0.006 & 1.000 \\
\hline SF36 MH & $39.1(18.6-59.5)$ & $45.9(18.6-59.5)$ & $50.4(27.7-61.8)$ & 0.001 & $<0.001$ & $<0.001$ \\
\hline SF36 PHC & $42.0(14.9-63.3)$ & $51.1(29.2-61.2)$ & $55.9(22.1-61.0)$ & 0.012 & $<0.001$ & 0.018 \\
\hline SF36 MHC & $41.8(19.1-61.0)$ & $50.0(24.3-61.3)$ & $52.9(28.1-58.9)$ & $<0.001$ & $<0.001$ & 0.004 \\
\hline BDI & $8.5(0.0-35.0)$ & $0.5(0.0-32.0)$ & $0.0(0.0-24.0)$ & $<0.001$ & $<0.001$ & 0.130 \\
\hline
\end{tabular}

BAI: Back Anxiety Inventory; BDI: Back Depression Inventory; BP: Bodily Pain; ER: Emotional Role Functioning; GH: General Health Perceptions; MH: Mental Health; MHC: Mental Health Component; PF: Physical Functioning; PR: Physical Role Functioning; PHC: Physical Health Component; SF: Social Role Functioning; V: Vitality.

*Wilcoxon signed rank test with Bonferroni correction.

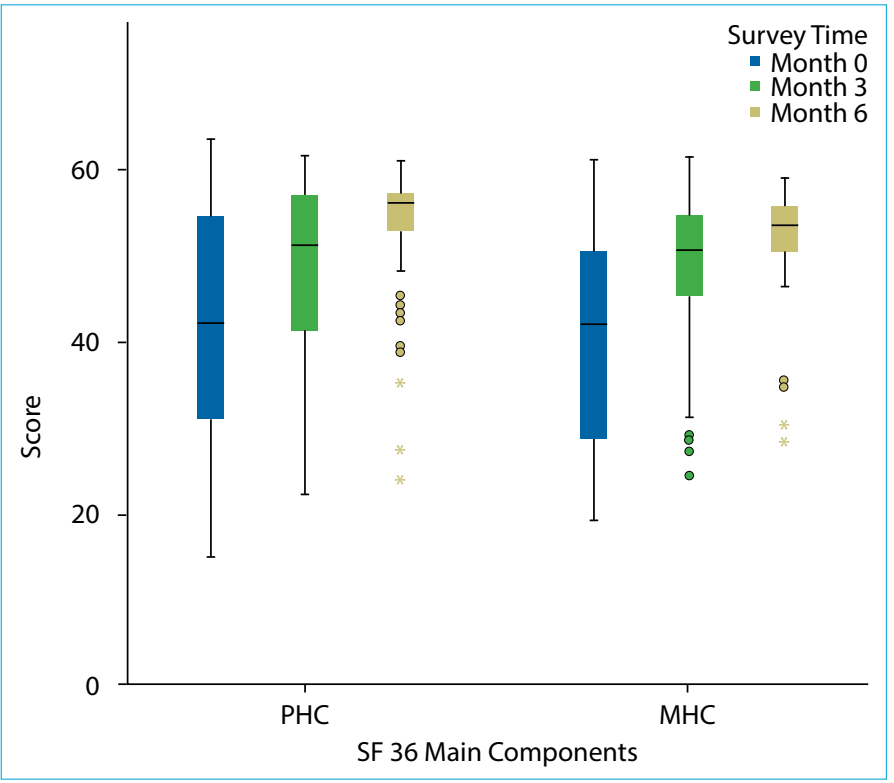

Figure 1. Boxplots of Short Form-36 main components.

the first and third survey results, and a statistically significant increase in MHC score, but not in PHC score, between the second and third survey results (Table1 and Figure 1).

Concerning BDI and BAI scores, there was a statistically significant decrease between the first and second surveys and between the first and third surveys, whereas there was no statistically significant difference between the second and third surveys (Table 1 and Figure 2).

In 38 patients who were illiterate or who held a primary school degree, there was a statistically significant increase between the first and second measurements and no statistically significant difference between the second and third measurements concerning PF, FR, and BP scores of SF-36. The comparative analyses of $\mathrm{BDI}$ and $\mathrm{BAI}$ scores point out a statistically significant decrease between the first and second measurements and between the first and third measurements, and no statistically significant difference between the second and third measurements (Table 2).

\section{DISCUSSION}

Published studies on psychological disorders in patients with TB are limited, although TB is a chronic infectious disease that is likely to cause serious psychological problems because of the fear of social stigma. ${ }^{[15,16]}$ In this study, we investigated changes in the quality of life and mental health of patients with TB during treatment.

Gustafson et al. defined male sex, advanced age, adult crowding at home, and poor quality of housing as independent risk factors for TB. ${ }^{[17]}$ The results of our study are consistent with the results of Gustafson et al. Disorders that develop simultaneously, such as depression, are likely to deteriorate during anti-TB treatment, and medications used in the anti-TB treatment are likely to affect mental health adversely. The mental health status of these patients may affect adherence to treatment. ${ }^{[18]}$ The present study showed an improvement in the quality of life and a decrease in the levels of depression and anxiety when the results before and after treatment were compared. The 
Table 2. Comparative statistical analysis results for SF-36, BDI and BAI scores in patients that were illiterate or who held a primary school degree (in months 0, 3 and 6)

\begin{tabular}{|c|c|c|c|c|c|c|}
\hline & Month 0 (1) & Month 3 (2) & Month 6 (3) & $p(1-2)^{*}$ & $p(1-3)^{*}$ & p (2-3)* \\
\hline SF36 PF & $37.2(15.2-57.1)$ & $47.7(25.7-57.1)$ & $57.1(17.3-57.1)$ & 0.003 & $<0.001$ & 0.101 \\
\hline SF36 PR & $28.0(28.0-56.2)$ & $56.2(28.0-56.2)$ & $56.2(28.0-56.2)$ & 0.289 & 0.001 & 0.199 \\
\hline SF36 BP & $49.4(24.2-62.7)$ & $53.7(37.5-62.7)$ & $62.7(42.2-62.7)$ & 0.018 & $<0.001$ & 0.117 \\
\hline SF36 GH & $42.9(26.5-57.9)$ & $48.0(26.5-60.3)$ & $52.0(32.2-62.6)$ & 0.001 & $<0.001$ & 0.041 \\
\hline SF36V & $40.8(30.1-63.3)$ & $51.4(37.2-63.3)$ & $58.5(34.9-63.3)$ & $<0.001$ & $<0.001$ & 0.030 \\
\hline SF36 ER & $55.3(23.7-55.3)$ & $55.3(23.7-55.3)$ & $55.3(23.7-55.3)$ & 0.154 & 0.012 & 1.000 \\
\hline SF36 MH & $36.8(23.2-57.3)$ & $45.9(30.0-57.3)$ & $50.4(30.0-61.8)$ & 0.002 & $<0.001$ & 0.001 \\
\hline SF36 PHC & $38.7(14.9-63.3)$ & $46.1(29.2-61.2)$ & $53.8(22.1-61)$ & 0.015 & $<0.001$ & 0.101 \\
\hline SF36 MHC & $41.7(21.9-57.6)$ & $49.8(27.1-61.3)$ & $52.1(28.1-58.9)$ & 0.003 & $<0.001$ & 0.009 \\
\hline BDI & $9.5(0.0-35.0)$ & $2.5(0.0-21.0)$ & $0.0(0.0-21.0)$ & $<0.001$ & $<0.001$ & 0.154 \\
\hline
\end{tabular}

BAI: Back Anxiety Inventory; BDI: Back Depression Inventory. BP: Bodily Pain; ER: Emotional Role Functioning; GH: General Health Perceptions; MH: Mental Health; MHC: Mental Health Component; PF: Physical Functioning; PR: Physical Role Functioning; PHC: Physical Health Component; SF: Social Role Functioning; V: Vitality.

*Wilcoxon signed rank test with Bonferroni correction.

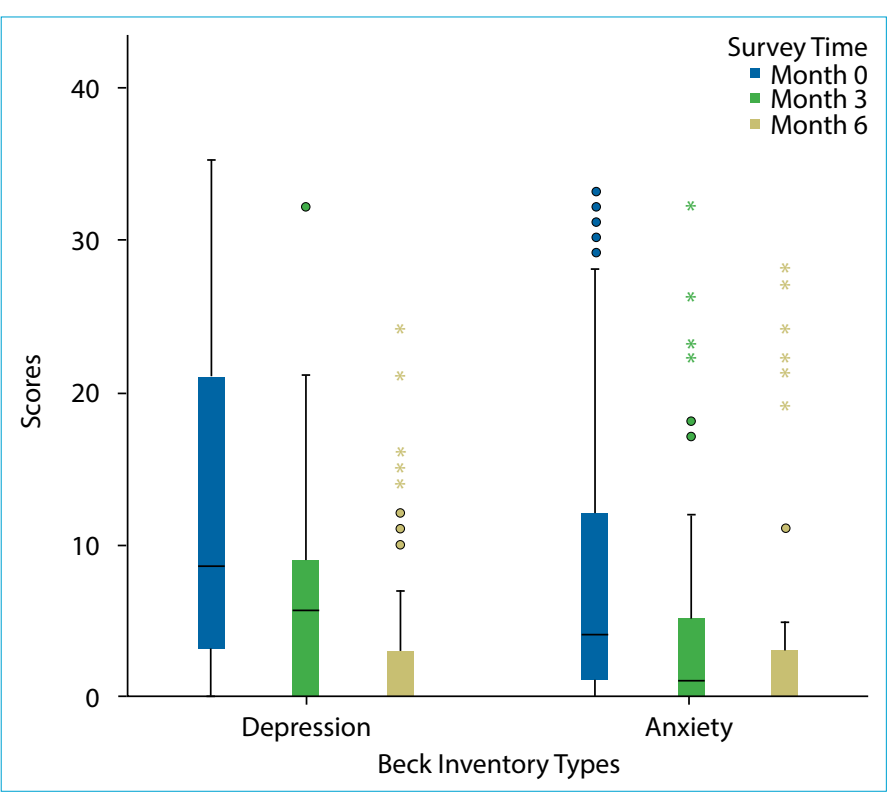

Figure 2. Boxplots of Beck Depression and Beck Anxiety Inventories.

findings suggest that anti-TB treatment does not cause psychological disorders in patients; on the contrary, the treatment improves the quality of life and mental health.

SF-36 scores were lower in the measurement conducted before the commencement of treatment when compared with the scores obtained in the third and sixth months of treatment. The scores increased over time, particularly in the third month of treatment. The 6-month SF-36 scores were significantly higher than the scores obtained before treatment; however, the scores at six months were significantly better than the scores at three months in half of the subscales. A similar study showed that health-related quality of life improved significantly in the sixth month of treatment in active patients with TB. ${ }^{[19]}$

Given that studies were mostly cross-sectional constitutes a limitation to determining the effects of the treatment process on patients' mental health and quality of life. This is a significant finding of our study given that BDI, BAI, and quality of life scores indicate improvement in patients, although no additional psychiatric treatment was planned.

Concerning $\mathrm{BDI}$ and $\mathrm{BAl}$, the high scores obtained the commencement of treatment reduced significantly in the second measurement conducted at the end of intensive treatment. While the differences between the first and second surveys and the first and third surveys were statistically significant, the scores of the second and third surveys were not significantly different. This may have been because substantial clinical recovery was seen in patients with TB after the end of the intensive treatment period, i.e., the first three months. Depression and anxiety in patients with at the beginning of treatment lowered significantly with the decrease in the dose of medications and recovery in TB symptoms after the intensive treatment period, whichleads us to believe that the mental disorders co-occurring with TB are mostly in the form of adjustment disorders. 
The major limitation of this study was that a psychiatric diagnosis scale was not used in this study. However, this research is still important in that, as an observational study, our findings suggest that TB treatment has positive effects on quality of life and the treatment of mental disorders in patients with TB.

\section{CONCLUSION}

The results suggest that the mental condition of patients with TB should be assessed thoroughly, and psychiatric medication treatment should not be planned when there is no diagnosis of depression or anxiety disorder. Additional medication is likely to cause challenges because of side effects and drug interactions in patients who already rely heavily on medications for TB treatment.

\section{Disclosures}

Peer-review: Externally peer-reviewed.

Conflict of Interest: None declared.

Ethics Committee Approval: Permission for this study was received from the Permission of the study was received from Eskişehir Osmangazi University Faculty of Medicine Clinical Research Ethics board (Approval date:11 Dec 2014, Approval number: 04).

Authorship Contributions: Concept - F.K.; Design - F.K., U.B.; Supervision - I.Ü., U.B.; Materials - F.K.; Data collection \&/or processing - F.K., U.B.; Analysis and/or interpretation -F.K., i.Ü., H.Ö.; Literature search - F.K., U.B.; Writing - F.K.; Critical review - I.Ü, U.B.

\section{REFERENCES}

1. Mohajan HK. Tuberculosis is a fatal disease among some developing countries of the world. American Journal of Infectious Diseases and Microbiology 2015;3(1):18-31.

2. World Health Organization. Global tuberculosis report 2015. http://www.who.int/tb/publications/global_report/en/ (accessed online at March-19-2016)

3. Maurer J, Rebbapragada V, Borson S, Goldstein R, Kunik ME, Yohannes AM, et al. Anxiety and depression in COPD: current understanding, unanswered questions, and research needs. Chest 2008;134(4 Suppl):43S-56S.

4. Moussas G, Tselebis A, Karkanias A, Stamouli D, Ilias I, Bratis $D$, et al. A comparative study of anxiety and depression in patients with bronchial asthma, chronic obstructive pulmonary disease and tuberculosis in a general hospital of chest diseases. Ann Gen Psychiatry 2008;7:7.

5. Nault D, Borycki E, editors. Comprehensive Management of Chronic Obstructive Pulmonary Disease. Hamilton: BC Dekker Inc; 2002.p.215-44.
6. Hansel NN, Wu AW, Chang B, Diette GB. Quality of Life in Tuberculosis: Patient and Provider Perspectives. Qual Life Res 2004;13(3):639-52.

7. Baral SC, Aryal Y, Bhattrai R, King R, Newell JN. The importance of providing counselling and financial support to patients receiving treatment for multi-drugresistant TB: mixed method qualitative and pilot intervention studies. BMC Public Health 2014;14:46.

8. Ware JE Jr, Sherbourne CD. The MOS 36-item Short-Form Health Survey (SF-36). I. Conceptual framework and item selection. Med Care 1992;30(6):473-83.

9. Aydemir Ö. Konsültasyon-liyezon psikiyatrisinde yaşam kalitesi ölçümü: Kısa Form-36 (SF-36). 3 Psikiyatri Psikoloji Psikofarmakoloji (3P) Dergisi 1999;7(Ek 2):14-22.

10. Koçyiğit H, Aydemir Ö, Ölmez N, Memiş A. SF-36'nın Türkçe için güvenilirliği ve geçerliliği. Ege Fizik Tedavi ve Rehabilitasyon Dergisi 1999.

11. BECK AT, WARD CH, MENDELSON M, MOCK J, ERBAUGH J. An inventory for measuring depression. Arch Gen Psychiatry 1961;4:561-71.

12. Hisli N. Beck Depresyon Envanterinin geçerliliği üzerine bir çalışma. Psikoloji Dergisi 1988;6:118-26.

13. Beck AT, Epstein N, Brown G, Steer RA. An inventory for measuring clinical anxiety. J Consult Clin Psychol 1988;56(6):8937.

14. Ulusoy M, Sahin NH, Erkmen H. Turkish version of the Beck Anxiety Inventory: Psychometric properties. Journal of Cognitive Psychotherapy 1998;12(2):163-72.

15. Baral SC, Karki DK, Newell JN. Causes of stigma and discrimination associated with tuberculosis in Nepal: a qualitative study. BMC Public Health 2007;7:211.

16. Hansel NN, Wu AW, Chang B, Diette GB. Quality of life in tuberculosis: patient and provider perspectives. Qual Life Res 2004;13(3):639-52.

17. Gustafson P, Gomes VF, Vieira CS, Rabna P, Seng R, Johansson $\mathrm{P}$, et al. Tuberculosis in Bissau: incidence and risk factors in an urban community in sub-Saharan Africa. Int J Epidemiol 2004;33(1):163-72.

18. Doherty AM, Kelly J, McDonald C, O'Dywer AM, Keane J, Cooney J. A review of the interplay between tuberculosis and mental health. Gen Hosp Psychiatry 2013;35(4):398-406.

19. Marra CA, Marra F, Colley L, Moadebi S, Elwood RK, Fitzgerald JM. Health-related quality of life trajectories among adults with tuberculosis: differences between latent and active infection. Chest 2008;133(2):396-403.

20. Peltzer K, Naidoo P, Matseke G, Louw J, McHunu G, Tutshana B. Prevalence of psychological distress and associated factors in tuberculosis patients in public primary care clinics in South Africa. BMC Psychiatry 2012;12:89. 